\title{
Perceived Discrimination and Adolescent Sleep in a Community Sample
}

\author{
BRIDGET J. GOOSBY, JACOB E. CHEADLE, WHITNEY STRONG- \\ BAK, TAYLOR C. ROTH, AND TIMOTHY D. NELSON
}

Sleep is a key restorative process, and poor sleep is linked to disease and mortality risk. The adolescent population requires more sleep on average than adults but are most likely to be sleep deprived. Adolescence is a time of rapid social upheaval and sensitivity to social stressors including discrimination. This study uses two weeks of daily e-diary measures documenting discrimination exposure and concurrent objective sleep indicators measured using actigraphy. We assess associations between daily discrimination and contemporaneous sleep with a diverse sample of adolescents. This novel study shows youth with higher average discrimination reports have worse average sleep relative to their counterparts. Interestingly, youth reporting daily discrimination have better sleep the day of the report than youth who do not.

Keywords: sleep, adolescence, discrimination, actigraphy

Sleep is an important restorative process instrumental in regulating physiologic systems, cognition, and behavioral outcomes (Balbo, Leproult, and Van Cauter 2010; Kliewer and Lepore 2014). Sleep quality and duration are associated with an array of morbidities including metabolic conditions, cardiovascular dis- ease, and major depression (Irwin 2015). Because adolescents are a population vulnerable to poor sleep during a key developmental period of significant physiological and environmental change, they are an important group to systematically assess with regard to sleep patterns and social conditions linked to chronic

Bridget J. Goosby and Jacob E. Cheadle are Happold Associate Professors of Sociology and co-directors of the LifeHD: Life in Frequencies Health Disparities Research Lab at the University of Nebraska-Lincoln. Whitney Strong-Bak is a doctoral candidate and graduate research assistant in the School Psychology Program. Taylor C. Roth is a doctoral student and graduate research assistant in the department of psychology at the University of Nebraska-Lincoln. Timothy D. Nelson is associate professor of psychology and director of the Pediatric Health Lab at the University of Nebraska-Lincoln.

(C) 2018 Russell Sage Foundation. Goosby, Bridget J., Jacob E. Cheadle, Whitney Strong-Bak, Taylor C. Roth, and Timothy D. Nelson. 2018. "Perceived Discrimination and Adolescent Sleep in a Community Sample." RSF: The Russell Sage Foundation Journal of the Social Sciences 4(4): 43-61. DOI: 10.7758/RSF.2018.4.4.03. This research was supported by grant K01 HD 064537 from the Eunice Kennedy Shriver Institute of Child Health and Human Development (Bridget Goosby, PI) and by the University of Nebraska Social Sciences and Behavioral Research Consortium (SBSRC). We appreciate the helpful comments from Thomas McDade and Kathleen Mullan Harris. Direct correspondence to: Bridget J. Goosby at bgoosby2@unl.edu, University of Nebraska-Lincoln, Department of Sociology, 741 Oldfather Hall, Lincoln, NE 68588; Jacob E. Cheadle at jcheadle2@unl.edu, University of Nebraska-Lincoln, Department of Sociology, 732 Oldfather Hall, Lincoln, NE 68588; Whitney Strong-Bak at whitney.strong@huskers.unl.edu, Munroe-Meyer Institute, 985450 Nebraska Medical Center, Omaha, NE 68198; Taylor C. Roth at taylor.roth@huskers.unl.edu, University of Nebraska-Lincoln, Department of Psychology, 238 Burnett Hall, Lincoln, NE 68588; and Timothy D. Nelson at tnelson3@unl.edu, University of Nebraska-Lincoln, Department of Psychology, 319 Burnet Hall, Lincoln, NE 68588.

Open Access Policy: RSF: The Russell Sage Foundation Journal of the Social Sciences is an open access journal. This article is published under a Creative Commons Attribution-NonCommercial-NoDerivs 3.0 Unported License. 
disease risk (Becker, Langberg, and Byars 2015; Park et al. 2016). A growing literature indicates that sleep may function as a key mechanistic pathway through which exposure to social stressors such as discrimination or other social exclusionary experiences decrease health (Lewis et al. 2013; Hicken et al. 2013). This research, however, primarily focuses on adult populations with inferences based mostly on self-reported rather than objective sleep measures. This study fills the gap in existing sleep research by examining adolescents, a key atrisk group for poor sleep and stressful social dynamics, using a lengthy window of objective actigraphy-based sleep measures.

Adolescence is a critical time to study the impact of social stressors on sleep because they are more likely, on average, to report difficulty falling asleep, staying asleep, and to be chronically sleep deprived (Yip 2014; Carskadon 1990). For adolescents, sleep is instrumental in the ability to regulate negative emotions and coping with stressful conditions (Dahl 1999; ElSheikh et al. 2010). Although frequency of dayto-day discrimination exposure as well as accumulated discrimination has been linked to poorer mental and physical health outcomes, less is known about the role of discrimination for sleep patterns among adolescents (Schmitt et al. 2014; Goosby et al. 2015; Torres and Ong 2010). To address these gaps, this study uses novel pilot data from a diverse sample of adolescents combining survey data, daily electronic-diaries (e-diaries), and actigraphybased sleep measures to address the following questions (Eufemia et al. 2012): In early to midadolescence, do experiences of discrimination or unfair treatment affect sleep (both quantity and quality) consistently over time? Do daily fluctuations in such experiences influence nightly sleep variability?

\section{LITERATURE REVIEW}

Public health concern is growing over sleep quality and duration, also known as sleep health, in the United States. Nearly 25 percent of the U.S. population report insomnia complaints and 10 percent meet clinical criteria for insomnia (see Irwin 2015). Due to the importance of sleep for numerous health and behavioral outcomes, interest in studying sleep qual- ity and duration is considerable (Kingsbury, Buxton, and Emmons 2013; Gregory and Sadeh 2012; Irwin 2015). Moreover, increasing evidence suggests that sleep characteristics differ across populations and are linked to social and environmental conditions.

Sleep patterns appear to vary by sociodemographic factors that include age, socioeconomic conditions, race and ethnicity, and education (Hale, Emanuele, and James 2015). Adolescents, for example, as a group require more sleep on average (approximately nine hours) but are less likely to actually get adequate sleep than adults (Becker, Langberg, and Byars 2015). People living in economically disadvantaged and segregated neighborhoods also have poorer sleep quality, in part due to the excess noise and crowding found frequently in such environments (Hale, Emanuele, and James 2015; Massey 2004). Race differences are also documented, particularly among African Americans relative to whites; African Americans are a population at higher risk for living in or near economically disadvantaged neighborhoods and at higher risk for disruptive chronic stressors (Williams 2012). Consequently, this population commonly shows signs of harmful sleep patterns by sleeping both shorter and longer durations than the recommended average and accompanied by poorer sleep quality that is less restorative (Kingsbury, Buxton, and Emmons 2013; Mezick et al. 2008; Profant, Ancoli-Israel, and Dimsdale 2002).

Yet much of the literature has used subjective sleep reports rather than objective measures of sleep, and that subjective reports have relatively low reliability relative to more objective measures is well documented (Short et al. 2012, 2013). Respondents asked retrospectively about their sleep duration, for example, are more likely to overestimate duration and underestimate number of awakenings during the night; adolescents in particular may tend to only report more salient, recent information (Wolfson et al. 2003). Daily diaries are another self-report approach to measuring sleep that has the advantage of capturing day-to-day variation usually over an extended period to characterize sleep. Use of temporally proximal data on sleep habits across a range of days is more 
strongly correlated with laboratory-based gold standard measures of sleep quality than oneshot, long-term subjective self-reports (Wolfson et al. 2003). Among self-report measures, sleep diaries appear to provide the most reliable sleep measures, particularly among adolescents (Short et al. 2013). Sleep diaries, however, tend to overestimate total objective sleep time and underestimate awakening frequency during the night because individuals may not always be aware of waking during the night or other factors that may make sleep more or less restful (Short et al. 2012; Wolfson et al. 2003).

Although self-reported measures of sleep can provide meaningful information and in some cases be correlated with objective sleep measures, they are not as reliable in accurately measuring total sleep duration, waking after sleep onset, or activity during sleep. In nonlaboratory settings, the current state-of-the-art method for objectively measuring sleep dimensions is actigraphy (Short et al. 2012). Actigraphy uses accelerometers placed on the wrist to document sleeping and waking states (Marino et al. 2013). Though actigraphy cannot measure specific sleep architecture or sleep staging, it has been validated to accurately measure distinctions between sleeping and waking along with total sleep time (TST) in both sleep disordered and general populations (Ancoli-Israel et al. 2003). Actigraphs are particularly useful for nonlaboratory studies because they can be worn for extended periods for tracking sleep patterns, which cannot be feasibly measured in sleep labs. Despite the convenience of actigraphy for measuring sleep in the field, use of it is not yet as common in studies of adolescence. We broadly characterize adolescents' sleep using a rich set of actigraphy measures taken nightly over a two-week period, emphasizing a key exclusionary social experience, discrimination, and relationships to different features of sleep.

\section{Discrimination and Sleep}

The need for social bonding and connection is among the most basic of all human needs (Baumeister and Leary 1995), and our health suffers when our needs for social connection are not satisfied (Cacioppo and Patrick 2009). Social exclusion has widespread implications for health, health behaviors generally, and sleep specifically (Hawkley et al. 2003; Duclos, Wan, and Jiang 2014; on sleep, Pereira, Meier, and Elfering 2013; Sladek and Doane 2014). A key dimension of social exclusion is the perception of discrimination or unfair, prejudicial, and exclusionary treatment based on certain characteristics or stigmatized identities such as race, obesity, gender, and sexuality (among others). Specifically, discrimination has been linked to a variety of health outcomes including poorer self-rated health (Krieger et al. 2011), high blood pressure (Lewis et al. 2009), vascular resistance (Guyll, Matthews, and Bromberger 2001), adiposity (Lewis et al. 2011), increased inflammation (Lewis et al. 2010), and higher allostatic load (Brody et al. 2014). As early as adolescence, discrimination is linked to worse self-rated health (Priest et al. 2013), depressive symptoms (Hope, Hoggard, and Thomas 2015), anger (Wong, Eccles, and Sameroff 2003), as well as elevated systolic and diastolic blood pressure, and higher C-reactive protein (CRP) (Goosby et al. 2015). Although less is known about the links between discrimination and sleep quality than some other stressors, research suggests that even the anticipation and rumination on social exclusion can decrease sleep quality (Hicken et al. 2013; Åkerstedt 2006; Åkerstedt, Kecklund, and Axelsson 2007).

In findings from sleep lab clinical studies, discrimination exposure predicts less time in restorative sleep stages and greater daytime fatigue in adults (Thomas et al. 2006). In nonclinical, larger scale surveys, differences in subjective sleep quality and wakefulness after falling asleep among African Americans relative to whites are attenuated (though not eliminated) by reports of chronic discrimination (Lewis et al. 2013) and racism-related vigilance (Hicken et al. 2013). Although the evidence from adults points to a key role for perceived discrimination in reducing sleep quality, less is known about links between discrimination and adolescent sleep. Limited available evidence suggests that the same pattern for adults may also hold for youth; adolescents who retrospectively report experiencing higher levels of discrimination over the past year reported lower sleep quality and quantity in their daily sleep diary reports (Yip 2014).

Discrimination exposure and sleep are dy- 
Figure 1. CCFW Study Design and Discrimination Measures

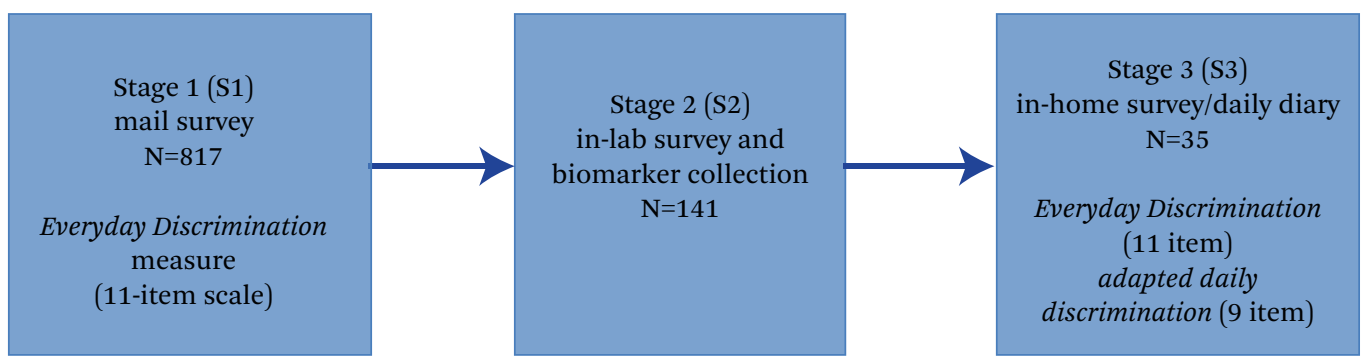

Source: Authors' compilation.

namic processes, but most studies in this area have so far relied heavily on retrospective measures of both discrimination and self-reported sleep quality. Despite the cross-sectional nature of these studies, the links between discrimination and sleep, as well as for other health outcomes, are robust. In a study of Latino youth, researchers Lucas Torres and Anthony Ong use daily diary information documenting both discrimination events and depressive symptoms found a day lag among youth who reported discrimination for subsequent elevated depressive symptoms (2010). Both this study and Tiffany Yip's of 2014 suggest that the accumulation of chronic discrimination may have long-term implications for subsequent sleep; however, neither study examined daily discrimination experiences and sleep contemporaneously, thus leaving an open question regarding whether discrimination can have more immediate consequences for youth sleep patterns.

Our study aims to address these gaps in the literature by first assessing the temporal relationship between daily experiences of discrimination and subsequent objective dimensions of sleep among a sample of adolescents. We explore sleep both as average sleep trends over a two-week period and as day-to-day fluctuations in sleep. Our first hypothesis (H1) posits that the accumulation of discriminatory experiences is related to poorer average sleep. Our second hypothesis $(\mathrm{H} 2)$ states that adolescent sleep will be poorer on days that adolescents perceive they have been discriminated against.

\section{DATA AND METHODS}

Data in this study come from the Community Connections and Family Wellness Study, which was designed to assess the intergenerational health and well-being of parent-child dyads and was originally conceived of as a two-part pilot study comprising a mail survey screening for an in-lab component to develop and assess recruitment protocols for a larger social neuroscience project (Falk et al. 2013). Sampling and data collection methods included three stages ranging over two years. Figure 1 outlines the stages (S1-S3) of data collection for this multistage sample. In stage 1, in collaboration with a local school system in a mid-sized Midwestern city, we contacted a subset of 2,181 (1,000 white, 1,181 African American or biracial) middle- and high school students ages eleven through fourteen in the school district during the fall of 2014. Two survey packets, one for the parent or guardian and another for the student, were mailed to each family in summer 2014 with a \$2 incentive for each. A total of 817 parent-guardian and child dyads completed the mail surveys in stage 1 .

The stage 2 data collection took place from December 2014 to June 2015 with a subset of 141 parent-child pairs from stage 1 who expressed interest in participating in future studies. These participants were invited to visit a laboratory space on a local college campus where anthropometrics, biospecimans, experimental, and additional survey data were collected. Participants in this phase of the study were restricted to families of white, African American, and biracial youth with one African American parent. A \$20 incentive was given to each participant along with meal vouchers for participants who were interested in visiting campus (based on responses to an incentive question during stage 1). The overall response 
rate for participation in the stage 2 portion of the study was 32.4 percent.

Approximately a year later, a subset of forty parent-youth dyads from the in-lab participant pool were recruited for a third stage (stage 3) in-home data collection between February and May 2016. At the initial home visit, after parental consent and child assent, the parent and child independently completed baseline survey measures of health, daily experiences, diet, sleep behavior, and anthropometric measurements. Participants were then trained to use ActiGraph Black/wActiSleep BT and Red/wGTXBT wristbands and the daily online e-diary procedure (Eufemia et al. 2012). Both the parent and youth were sent an email nightly with a link to their e-diary, which was formatted for use on either a computer or smart device. Both the parent and youth were asked to wear the actigraph wristband all day and night for fourteen consecutive days to measure sleep activity. At the end of the period, parents and youth returned the actigraph wristbands and, to facilitate recruitment and retention of participants, were compensated with cash (up to $\$ 200$ for the family based on adherence to the study protocol). High rates of protocol adherence (approximately 90 percent) were obtained with both e-diary and actigraph protocols.

Of the 113 families contacted for participation, fifty-eight could not be reached or did not return messages, and thirteen refused, had moved, or were otherwise ineligible. Based on the race of the child, twenty-one of the families were white, four were African American, and fifteen were biracial (one biological African American parent). However, because of missing sleep and biological data, only thirty-five families were used in these analyses. The distribution across race groups in the current analytic sample was twenty-one white, four African American, and ten biracial adolescents. Of these, sixteen were male and nineteen were female. For this study, African American and biracial youth were combined into one category because of the small sample sizes.

\section{MEASURES}

Sleep measures are derived from the mathematical decomposition of accelerometer data recorded continuously on the actigraph wrist- bands. The devices were configured to collect data at $60 \mathrm{hz}$ with the idle sleep mode enabled. The actigraphy measures were calculated using the ActiLife 6 software package (ActiGraph 2012). The actigraph data were segmented into sixty-second epochs and wear time validation was assessed using Troiano's algorithm (Troiano et al. 2008). Sleep analyses then utilized Sadeh's algorithms and were manually adjusted using bed and wake time information collected in the nightly e-diary (Sadeh 2011; Sadeh, Sharkey, and Carskadon 1994).

We present a diverse number of sleep measures, including multiple measures of both sleep duration and quality, in this study. Descriptions are presented in table 1 for reference. Example data are presented in figure 2 for illustrative purposes. The lightly shaded sleep period denotes the time in bed and the darker shaded period denotes the time asleep. The top chart in figure 2 shows a highly efficient night of sleep with only short interruptions as indicated by physical movement. The second chart shows much less efficient and poorer sleep with longer periods of disrupted wakefulness and delayed sleep onset. In addition to the actigraphy data, the bottom row of table 1 describes a sleep factor score that was constructed after conducting exploratory factor analysis of the following sleep quality items: sleep efficiency, waking after sleep onset (WASO), average awakening length, movement index, and sleep fragmentation. The scale was then validated using a confirmatory factor analysis to provide an overall sleep quality measure. All sleep measures in the statistical analysis were standardized over the entire sleep distribution to facilitate effect size comparisons.

\section{Discrimination}

The key predictor of sleep in this study, measures of discrimination, are operationalized three ways. First, the Williams Everyday Discrimination Scale (EDiS) adapted for adolescents was collected during the initial stage 3 home visit before the actigraphy sleep data was collected (Williams et al. 1997). The EDiS comprised eleven ordinal items categorized from never (0) to almost every day (5). Items were prefaced with the question "In your day-to-day life, how often do you experience the follow- 
Table 1. Description of Sleep Measures

\begin{tabular}{|c|c|}
\hline Measure & Description \\
\hline Latency & $\begin{array}{l}\text { Sleep latency is the time it takes to fall asleep, as measured by the } \\
\text { difference between bedtime and the onset of sleep (measured in } \\
\text { minutes). }\end{array}$ \\
\hline Efficiency & $\begin{array}{l}\text { Sleep efficiency is the number of minutes scored as being asleep } \\
\text { divided by the total number of minutes in bed. } 85 \% \text { sleep efficiency is } \\
\text { typically considered normal sleep efficiency, so higher values } \\
\text { indicated better sleep for the amount of time spent in bed. }\end{array}$ \\
\hline Total minutes & Total minutes spent in bed. \\
\hline Total sleep time & Total sleep time is the number of minutes scored as being asleep. \\
\hline WASO & $\begin{array}{l}\text { Wake after sleep onset (WASO) is the total number of minutes awake } \\
\text { after the initial onset of sleep. Larger values indicate poorer sleep. }\end{array}$ \\
\hline Awakening frequency & $\begin{array}{l}\text { The number of different awakening episodes after the initial onset of } \\
\text { sleep. Higher values indicate more awakenings and poorer sleep. }\end{array}$ \\
\hline Average awakening length & $\begin{array}{l}\text { The average length, in minutes, of all awakening episodes. Higher } \\
\text { values indicate greater time spent awake for each awakening episode, } \\
\text { which reflects poorer sleep. }\end{array}$ \\
\hline Movement index & $\begin{array}{l}\text { The movement index is the percentage of epochs with y-axis counts } \\
\text { greater than zero in the sleep period. Thus higher values indicate } \\
\text { more movement and suggest less restful sleep. }\end{array}$ \\
\hline Fragmentation index & $\begin{array}{l}\text { The fragmentation index is a measure of restlessness and interruption } \\
\text { of sleep. It is calculated by the percentage of one minute sleep } \\
\text { periods versus all sleep periods. Higher values indicate more frequent } \\
\text { interruption of sleep (and, therefore, poorer sleep). }\end{array}$ \\
\hline Sleep fragmentation index & $\begin{array}{l}\text { The sum of the movement and fragmentation indices. Higher values } \\
\text { suggest greater microarousals and poorer sleep quality. }\end{array}$ \\
\hline Poor sleep factor & $\begin{array}{l}\text { CFA-derived factor score summarizing poor sleep quality using the } \\
\text { total actigraphy counts summed together over the sleep period, } \\
\text { efficiency, WASO, average awakening length, movement index, and } \\
\text { sleep fragmentation. }\end{array}$ \\
\hline
\end{tabular}

Source: Authors' compilation.

ing?" The scale covered a range of social exclusionary and unfair treatment situations that included being treated with less courtesy and less respect, receiving poorer service at restaurants and stores than other people, being insulted or treated poorly by teachers, and being threatened and harassed. Factor loadings were all greater than 0.6 and Cronbach's $=0.9$. The mean was calculated across items and scores were standardized across participants. Importantly, the EDiS is one of the most widely used scales in the area of health disparities research (Paradies 2006). It is also shown to have good reliability, validity, and measurement invariance across African American and white populations (on validity, Benjamins 2012; on mea- surement, Shariff-Marco et al. 2011; Kim, Sellbom, and Ford 2014). In short, a key advantage of EDis to measures of, for example, racism-related discrimination is that the EDiS captures discrimination-based social exclusion for a variety of groups, including white respondents.

Next, a series of binary items based on the EDiS were included in the daily e-diaries to indicate whether specific types of mistreatment had occurred over the course of the day. These items captured unfair or poor treatment at school, store, restaurant, or other public space. Five questions measured specific types of mistreatment drawn directly from EDis, such as "Over the course of the day, did you feel like 
Figure 2. Actigraph Sleep Data, Good (Top) and Poor (Bottom) Nights of Sleep
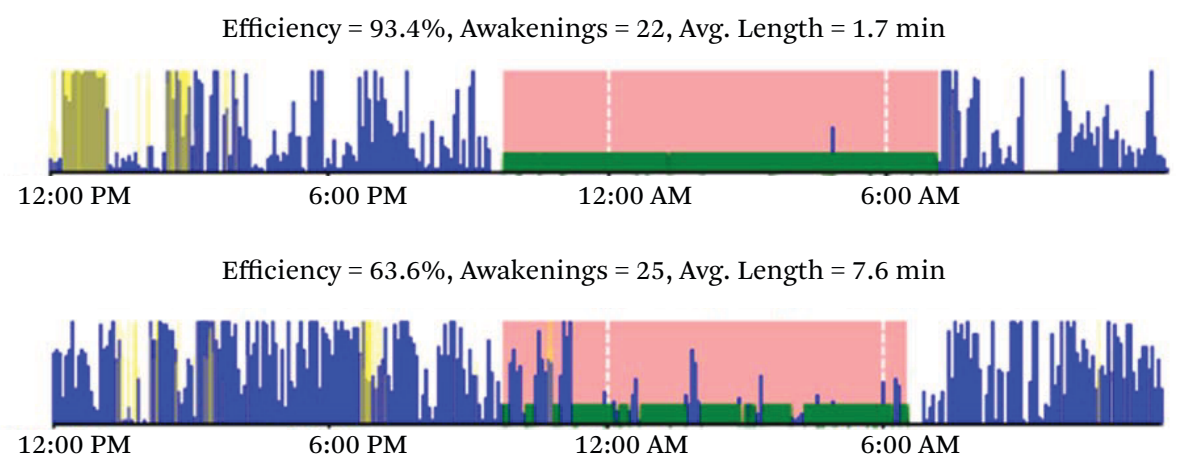

Source: Authors' calculations.

Note: Movement activity where lightly shaded area denotes period in bed and darker shaded area denotes time asleep.

you were called names or were insulted?" Four additional EDiS items asked whether participants felt that others thought they were not smart, were afraid of them, thought that they were dishonest, and better than them over the course of the day. These items are operationalized as a sum score at the daily level. The third measure is based on the average daily number of experiences, standardized across participants to facilitate comparison with the traditional EDiS instrument.

\section{Controls}

Biomarkers from dried blood spots from capillary whole blood were collected during the stage 2 in-lab data collection and were included in the current analyses as controls for potential markers of prior chronic disease risk. Blood spots were assayed for hemoglobin a1c (HbA1c), high sensitivity CRP, and Epstein-Barr virus (EBV) titers. Samples were stored at -20 degree freezer at the University of Nebraska and shipped overnight to the University of Washington Department of Laboratory Medicine for assays (Mark H. Wener, MD, director, Seattle, Washington). Hemoglobin Hba1c, a marker of the percentage average blood glucose over two to three months, is an indicator of diabetes risk, a condition correlated with poor sleep. The raw percentage Hba1c levels of respondents were derived from dried blood from $3.2 \mathrm{~mm}$ punch disc eluted in a buffer. The raw percentages were converted to the blood equivalent (B-E) value, which is the equivalent of conventional venous liquid blood samples. These values were used in this study and are used to determine cutoffs for normal $(<5.7$ percent), prediabetic (5.7-6.4 percent), and diabetic $(>=6.5$ percent) range (Potter, UW lab personal correspondence). CRP is a cell-mediated inflammatory marker that is strongly correlated with cardiovascular disease risk. CRP concentrations were also assayed from a $3.2 \mathrm{~mm}$ punch disc and eluted in a buffer. CRP values converted to serum equivalents using established clinical metrics (for example, NHANES) range from low $(<3 \mathrm{mg} / \mathrm{L})$, elevated $(3<10 \mathrm{mg} / \mathrm{L})$ to high $(10<)$ values likely due to acute infection (Pearson et al. 2003). Epstein-Barr antibodies (anti-EBV VCA IgG Ab), whose elevated presence is an indicator stress induced immunosuppression (McClure et al. 2010), were assayed and converted to plasma equivalent values as well. Little is known about its link to sleep. Both CRP and EBV were transformed using a hyperbolic sine transformation that is very similar to a log transformation (Burbidge, Magee, and Robb 1988). All scores were then standardized for use in statistical analyses.

Additional measures include waist-hip ratio from stage 2, standardized across participants to adjust for body size when the biological data were collected (Dalton et al. 2003). From the stage 3 e-diaries, daily somatic complaints as well as the two-week somatic complaint average was calculated from four ordinal items- 
none (1) to a lot (4)-capturing poor appetite, aches or pains or muscle-joint soreness, being tired for no reason, stomach ache or upset, and headaches. At the daily level, poor self-rated health (five categories, very good to very poor) is included as a standardized measure, along with a standardized person-average over the two-week study period. Finally, all models include an indicator for whether the child was biracial or African American, female, whether the focal parent is married, and whether the family income was greater than $\$ 45,000$, approximately 250 percent of the state poverty level collected at stage 1 (CFIN 2012). The number and age of children in the household were also included.

\section{Analytic Strategy}

The sleep measures comprise the key dependent variables of the analysis and have two key forms of dependency. First, the data are nested within individual participants. For this reason, the basic model is a two-level random-intercept model with each day's sleep nested within each participant (Raudenbush and Bryk 2002). The daily e-diary measures (discrimination, somatic complaints, SRH) are used to predict sleep that night; the remaining parameters reflect associations with average sleep over the study period. Because the child-means are controlled at the between participant level of the model, the daily measures are orthogonal to the between-subject random intercept and can be interpreted as within-person estimates (Allison 2005). Second, the within-subjects data are neither independent nor exchangeable after accounting for the nesting structure. Rather, an ordered dependency is captured using an autoregressive AR(1) residual structure (Chi and Reinsel 1989).

The models are presented in two ways. First, a between-subjects model including EDiS but not the daily e-diary measures is presented. This model captures the association between sleep and retrospective reports of perceived discrimination in day-to-day life collected during the in-home visit. Second, EDis is removed from the equation and the daily e-diary dis- crimination measures and their over-time average are included. The control and biological measures are included in all models reported. ${ }^{1}$

\section{RESULTS}

Descriptive statistics for the sleep variables are presented in table 2 for the total sample, by race and by gender. In general, participants fell asleep within two minutes and with a sleep efficiency rating of approximately 80 percent, which is less than normal healthy sleep efficiency ( 85 percent). The youth in this sample spent considerable time in bed, nearly $(521 / 60=) 8.7 \mathrm{hrs}$ and had a TST of nearly seven hours (413/60), well below the recommended sleep time for this age range of approximately nine hours. The wake after sleep onset averaged around ninety minutes and awakenings per night, of approximately two minutes each, totaled about twenty-three. Differences between groups were minimal other than an indication that biracial and African American youth had more fragmented or restless sleep than white youth, which falls in line with prior literature that finds African Americans have lower average sleep time and more disrupted sleep quality (Hale and Do 2007; Krueger and Friedman 2009).

Table 3 presents the descriptive demographic and health characteristics along with averages of both daily and retrospective discrimination levels reported in the sample. The youth in this sample were relatively disadvantaged, about half coming from homes making less than $\$ 45,000$ per year. Overall, retrospective EDiS average across items was low with the 1-value category reflecting "less than once a year" and the two-value category reflecting "a few times a year." However, youth reported 0.6 events per day, on average, suggesting that the retrospective EDiS may underreport the amount of discriminatory experiences that young people perceive when the questions are posed more closely in time to those experiences. It is also important that youths' average retrospective reports of discrimination using the EDiS showed similar average trends to our initial stage 1 sample of youth from which this 
Table 2. Descriptive Statistics of Sleep Measures

\begin{tabular}{|c|c|c|c|c|c|c|c|c|}
\hline & \multicolumn{4}{|c|}{ Full Analytic Sample } & \multicolumn{2}{|c|}{ Race } & \multicolumn{2}{|c|}{ Gender } \\
\hline & Mean & SD & Min & Max & White & Biracial & Male & Female \\
\hline Latency & 2.04 & 1.87 & 0 & 6 & 2.14 & 1.89 & 2.21 & 1.91 \\
\hline Efficiency & 79.87 & 11.06 & 45 & 100 & 79.57 & 80.33 & 79.23 & 80.40 \\
\hline Total minutes & 520.91 & 101.40 & 120 & 800 & 524.57 & 515.37 & 525.85 & 516.82 \\
\hline TST & 413.57 & 87.28 & 75 & 650 & 414.75 & 411.78 & 415.00 & 412.38 \\
\hline WASO & 90.44 & 55.33 & 0 & 250 & 92.92 & 86.69 & 92.26 & 88.94 \\
\hline Awakening frequency & 22.72 & 9.33 & 0 & 51 & 22.70 & 22.76 & 23.27 & 22.27 \\
\hline Average awakening length & 1.95 & 0.60 & 0 & 4 & 1.98 & 1.90 & 1.95 & 1.95 \\
\hline Movement index & 17.82 & 8.74 & 0 & 45 & 17.99 & 17.56 & 18.51 & 17.25 \\
\hline Fragmentation index & 11.65 & 7.95 & 0 & 38 & 10.84 & 12.89 & 11.39 & 11.87 \\
\hline Sleep frag. index & 29.47 & 13.82 & 0 & 70 & 28.79 & 30.50 & 30.02 & 29.02 \\
\hline Poor sleep factor score & 0.01 & 0.88 & -2 & 3 & 0.04 & -0.02 & 0.07 & -0.03 \\
\hline
\end{tabular}

Source: Community Connections and Family Wellness Study sleep data.

Table 3. Descriptive Statistics of Predictor Variables

\begin{tabular}{|c|c|c|c|c|c|c|c|c|}
\hline & \multicolumn{4}{|c|}{ Full Analytic Sample } & \multicolumn{2}{|c|}{ Race } & \multicolumn{2}{|c|}{ Gender } \\
\hline & Mean & SD & Min & Max & White & Biracial & Male & Female \\
\hline \multicolumn{9}{|l|}{ Between youth measures } \\
\hline EDiS & 1.22 & 1.08 & 0.00 & 3.91 & 1.20 & 1.24 & 1.15 & 1.27 \\
\hline African American or biracial & 0.40 & & 0.00 & 1.00 & & & 0.43 & 0.37 \\
\hline Female & 0.55 & & 0.00 & 1.00 & 0.57 & 0.51 & & \\
\hline Age & 13.66 & 1.12 & 12.00 & 16.00 & 13.62 & 13.72 & 13.49 & $13.80^{*}$ \\
\hline Parent married & 0.61 & & 0.00 & 1.00 & 0.63 & 0.58 & 0.57 & $0.65^{+}$ \\
\hline Number of children & 3.18 & 1.49 & 1.00 & 8.00 & 3.14 & 3.23 & 3.28 & 3.09 \\
\hline Income greater than $\$ 45,000$ & 0.50 & & 0.00 & 1.00 & 0.53 & $0.44^{*}$ & 0.57 & $0.43^{*}$ \\
\hline \multicolumn{9}{|l|}{$\begin{array}{l}\text { Biological between youth } \\
\text { measures }\end{array}$} \\
\hline CRP & 0.83 & 0.75 & 0.05 & 2.41 & 0.89 & $0.75^{*}$ & 1.20 & $0.53^{*}$ \\
\hline Hba1c & 5.36 & 0.47 & 4.60 & 7.30 & 5.22 & $5.56^{*}$ & 5.40 & $5.32^{+}$ \\
\hline EBV & 3.25 & 1.24 & 0.88 & 5.26 & 3.05 & $3.57^{*}$ & 3.00 & $3.47^{*}$ \\
\hline Waist-hip ratio & 0.84 & 0.10 & 0.67 & 1.02 & 0.85 & 0.84 & 0.90 & $0.79^{*}$ \\
\hline \multicolumn{9}{|l|}{ Daily diary questions } \\
\hline Discrimination ( $t$, count) & 0.57 & 1.26 & 0.00 & 7.00 & 0.51 & $0.68^{*}$ & 0.50 & 0.64 \\
\hline Discrimination ( $t$, avg.) & 0.55 & 0.76 & 0.00 & 3.64 & 0.49 & 0.65 & 0.48 & $0.61^{+}$ \\
\hline Somatic complaints $(t)$ & 1.37 & 0.47 & 1.00 & 4.00 & 1.45 & $1.26^{*}$ & 1.16 & $1.55^{*}$ \\
\hline Somatic complaints ( $t$, avg.) & 1.37 & 0.37 & 1.00 & 2.46 & 1.45 & $1.26^{*}$ & 1.16 & $1.55^{*}$ \\
\hline Poor SRH $(t, z)$ & 2.11 & 0.90 & 1.00 & 5.00 & 2.15 & 2.06 & 1.90 & $2.28^{*}$ \\
\hline Poor SRH ( $t$, avg.) & 2.11 & 0.67 & 1.00 & 3.31 & 2.15 & 2.06 & 1.90 & $2.28^{*}$ \\
\hline
\end{tabular}

Source: Community Connections and Family Wellness Study sleep data.

Note: Full analytic sample repeated observations $=475$, white observations $=286$, biracial observations $=189$, male observations $=215$, female observations $=260$, across 35 participants.

EDiS denotes Williams Everyday Discrimination scale taken during the in-home survey.

CRP (C-reactive Protein) units- mg/L; Hba1c (hemoglobin a1c) units- \% glycosolated hemoglobin over 2-3 month period; EBV (Epstein Barr antibodies) $-\mathrm{AU} / \mathrm{mL}$.

t-test comparisons indicated at ${ }^{+} p<.1,{ }^{*} p<.05$ 
Figure 3. Kernel Density Plot Everyday Discrimination Distribution

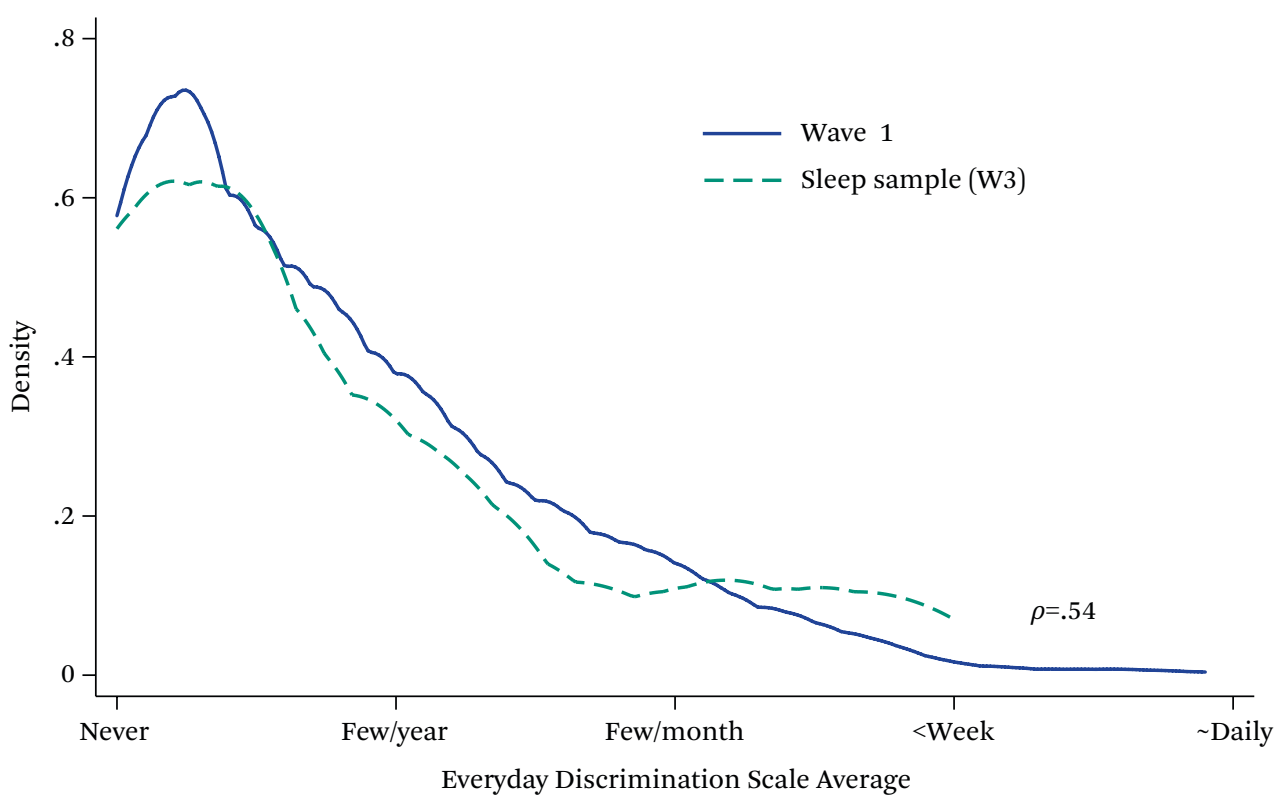

Source: Authors' calculations.

Note: Wave 1, $\mathrm{N}=688$. Analysis Sample, $\mathrm{N}=35$.

sample was drawn upon, who reported discrimination (see figure 3). Daily discrimination report counts were higher for biracial or African American youth, but they had fewer somatic complaints. Females reported both more somatic complaints and poorer self-rated health. Both biracial and female youth were more likely to come from disadvantaged families. The biracial youth had lower CRP values, as did females, but biracial and African American youth had higher average Hba1c and EBV antibody levels.

\section{Sleep Analysis}

A summary sleep analysis using the poor sleep factor score summary measure is presented in table 4 . As indicated in table 1 , this measure includes an array of highly intercorrelated sleep measures capturing many different features of actigraphy-based sleep assessment. Model A1 includes the home assessment of EDis (retrospective reports) and model A2 replaces this measure with the daily e-diary reports. Each standard deviation of EDiS (about one point on the ordinal average scale) is associated with a nearly 0.3 standard deviation $(p<.01)$ increase in poor sleep quality. Notably, the EDiS assessment is similar though smaller in magnitude than the two-week accumulation reported in model A2 $(b=0.352, p<.001)$. Together, these results suggest that the experience or perception of discrimination is positively associated with systematically poorer sleep. Surprisingly, however, the results also suggest that sleep may actually improve during the days when these negative experiences take place $(b=-.126, p<$ .01 ), in contrast to expectations. Given the nature of this effect, it indicates that youth who experience or perceive more discrimination have poorer average sleep. These youth, however, sleep slightly better on days when those events are reported, but not better overall relative to youth who do not experience such events. Thus, these global sleep findings are consistent with hypotheses 1 but contradict hypothesis 2 .

These models are reproduced in table 5 for sleep latency, overall sleep efficiency, total minutes in bed, and total sleep time. Indications are that, over time, discrimination is associated with increased sleep latency, lower efficiency, and more time in bed with lower TST. Effi- 
Table 4. Random Intercept Models, Poor Sleep Factor Score (z)

\begin{tabular}{|c|c|c|c|c|}
\hline & \multicolumn{2}{|c|}{$\mathrm{A} 1$} & \multicolumn{2}{|c|}{ A2 } \\
\hline & B & SE & B & SE \\
\hline \multicolumn{5}{|l|}{ Between youth measures } \\
\hline $\operatorname{EDiS}(z)$ & $0.289 * *$ & {$[0.089]$} & & \\
\hline African American or biracial & -0.245 & {$[0.190]$} & -0.130 & [0.182] \\
\hline Female & 0.002 & [0.093] & 0.048 & [0.085] \\
\hline Age (centered) & -0.217 & {$[0.221]$} & $-0.441^{+}$ & [0.234] \\
\hline Parent married & 0.218 & {$[0.194]$} & $0.314^{+}$ & [0.178] \\
\hline Number of children & 0.027 & {$[0.060]$} & $0.114^{+}$ & [0.064] \\
\hline Income greater than $\$ 45,000$ & -0.063 & {$[0.193]$} & -0.278 & [0.180] \\
\hline \multicolumn{5}{|c|}{ Biological between youth measures } \\
\hline $\operatorname{CRP}(z)$ & -0.034 & {$[0.111]$} & 0.143 & [0.107] \\
\hline Hba1c (z) & $0.195^{*}$ & {$[0.089]$} & $0.184^{*}$ & [0.082] \\
\hline $\operatorname{EBV}(z)$ & 0.031 & {$[0.094]$} & -0.083 & {$[0.086]$} \\
\hline Waist-hip ratio $(z)$ & -0.003 & {$[0.116]$} & -0.102 & [0.102] \\
\hline \multicolumn{5}{|l|}{ Daily diary questions } \\
\hline Discrimination ( $t$, count) & & & $-0.126^{* *}$ & [0.042] \\
\hline Discrimination $(t, a v g, z)$ & & & $0.352^{* * *}$ & [0.088] \\
\hline Somatic complaints $(t, z)$ & & & $0.142^{*}$ & [0.069] \\
\hline Somatic complaints ( $t$, avg, $z$ ) & & & 0.103 & [0.129] \\
\hline Poor SRH $(t, z)$ & & & 0.045 & [0.062] \\
\hline Poor SRH $(t$, avg, $z)$ & & & 0.064 & [0.105] \\
\hline Intercept & -0.293 & {$[0.322]$} & -0.066 & [0.288] \\
\hline \multicolumn{5}{|l|}{ Variance components } \\
\hline Between subject $(I n)$ & $-0.933^{* * *}$ & {$[0.183]$} & $-1.053^{* * *}$ & [0.188] \\
\hline Residual (In) & $-0.096 * *$ & {$[0.036]$} & $-0.118^{* * *}$ & [0.035] \\
\hline AR1 (rho) & $0.136^{*}$ & {$[0.057]$} & $0.094^{+}$ & [0.057] \\
\hline
\end{tabular}

Source: Community Connections and Family Wellness Study sleep data.

${ }^{+} p<.10 ;{ }^{*} p<.05 ;{ }^{* *} p<.01 ;{ }^{* * *} p<.001$

ciency, in particular is lower $(b=0.3)$ for those who experience more discrimination, but there are signs of greater sleep efficiency on specific days when discrimination events took place. As before, the daily discrimination measures contradict the hypothesis that negative experiences during the day decrease sleep quality. Instead these results suggest that youth who experience more discrimination generally have poorer sleep, but that sleep recovers relative to personal baseline on days when those experiences take place.

Results for waking from sleep over the night (WASO, awakening frequency, average awakening length) in table 6 and for the sleep indices (movement, fragmentation, sleep fragmenta- tion) in table 7 are consistent with the trends reported in tables 4 and 5 . Retrospective EDiS is associated with poorer sleep characteristics and is generally smaller but similar in magnitude to the standardized average of the daily reports. Moreover, on days when discrimination events are reported, youth tend to report better sleep quality as well. Overall, the sleep findings are consistent with hypotheses 1 , that discrimination is associated with average sleep quality across a range of sleep measures capturing time in bed. Contradictory to hypothesis 2 , however, sleep quality did not decrease on days when discrimination was reported. In fact, signs of a small recovery relative to individual baseline were again evident. Notably, retrospec- 
Table 5. Random Intercept Models, Sleep Latency, Efficiency, Minutes in Bed, and Total Sleep Time

\begin{tabular}{|c|c|c|c|c|c|c|c|c|}
\hline & \multicolumn{2}{|c|}{ Latency $(z)$} & \multicolumn{2}{|c|}{ Efficiency $(z)$} & \multicolumn{2}{|c|}{ Total Minutes (z) } & \multicolumn{2}{|c|}{ TST $(z)$} \\
\hline & B1 & B2 & $\mathrm{C} 1$ & C2 & D1 & D2 & E1 & E2 \\
\hline \multicolumn{9}{|l|}{ Between youth measures } \\
\hline $\operatorname{EDiS}(z)$ & $0.130^{+}$ & & $-0.302^{* *}$ & & 0.022 & & $-0.172^{*}$ & \\
\hline $\begin{array}{l}\text { African American or } \\
\text { biracial }\end{array}$ & -0.184 & -0.069 & 0.253 & 0.145 & -0.149 & -0.134 & 0.023 & -0.030 \\
\hline Female & -0.043 & 0.007 & 0.026 & -0.003 & -0.062 & -0.013 & -0.051 & -0.028 \\
\hline Age (centered) & $-0.312^{+}$ & $-0.394^{*}$ & 0.252 & $0.552^{*}$ & -0.024 & 0.151 & 0.114 & $0.439^{*}$ \\
\hline Parent married & 0.078 & 0.147 & -0.260 & $-0.345^{+}$ & -0.133 & -0.109 & $-0.312^{+}$ & $-0.345^{\star}$ \\
\hline Number of children & -0.004 & 0.074 & -0.018 & -0.093 & -0.059 & -0.035 & -0.070 & $-0.096^{+}$ \\
\hline $\begin{array}{l}\text { Income less than } \\
\$ 45,000\end{array}$ & 0.006 & -0.117 & 0.021 & 0.215 & 0.099 & 0.030 & 0.143 & 0.211 \\
\hline \multicolumn{9}{|l|}{ Biological between youth } \\
\hline \multicolumn{9}{|l|}{ measures } \\
\hline $\operatorname{CRP}(z)$ & $-0.163^{+}$ & -0.012 & 0.119 & -0.018 & 0.037 & $0.149^{+}$ & 0.096 & 0.103 \\
\hline Hba1c (z) & 0.014 & 0.004 & $-0.178^{*}$ & $-0.175^{*}$ & 0.093 & 0.071 & -0.022 & -0.038 \\
\hline EBV $(z)$ & -0.022 & -0.093 & -0.044 & 0.059 & 0.033 & -0.002 & 0.018 & 0.053 \\
\hline Waist-hip ratio $(z)$ & 0.016 & -0.017 & -0.016 & 0.100 & 0.009 & 0.029 & 0.002 & 0.090 \\
\hline \multicolumn{9}{|l|}{ Daily diary questions } \\
\hline Discrimination ( $t$, count) & & -0.034 & & $0.114^{* *}$ & & $-0.082^{+}$ & & 0.001 \\
\hline Discrimination $(t, a v g, z)$ & & $0.158^{*}$ & & $-0.307^{* * *}$ & & $0.162^{*}$ & & -0.063 \\
\hline Somatic complaints $(t, z)$ & & $0.131^{+}$ & & $-0.121^{+}$ & & $-0.138^{+}$ & & $-0.198^{* *}$ \\
\hline $\begin{array}{l}\text { Somatic complaints } \\
(t, \text { avg, } z)\end{array}$ & & 0.111 & & -0.111 & & 0.119 & & 0.046 \\
\hline Poor SRH $(t, z)$ & & -0.001 & & -0.047 & & 0.060 & & 0.003 \\
\hline Poor SRH $(t$, avg, $z)$ & & -0.064 & & -0.134 & & $-0.196^{*}$ & & $-0.237^{* *}$ \\
\hline Intercept & 0.056 & -0.016 & 0.314 & 0.001 & 0.294 & 0.216 & $0.490^{+}$ & 0.225 \\
\hline \multicolumn{9}{|l|}{ Variance components } \\
\hline Between subject $(I n)$ & $-1.524^{* * *}$ & $-1.953^{* *}$ & $-0.934^{* * *}$ & $-1.034^{* * *}$ & $-1.373^{* * *}$ & $-1.568^{* * *}$ & $-1.103^{* * *}$ & $-1.284^{* * *}$ \\
\hline Residual (In) & -0.035 & -0.039 & $-0.126^{* * *}$ & $-0.148^{* * *}$ & -0.050 & $-0.061^{+}$ & $-0.108^{* *}$ & $-0.119^{* * *}$ \\
\hline AR1 (rho) & $0.108^{*}$ & $0.109^{*}$ & $0.148^{\star \star}$ & $0.097^{+}$ & 0.041 & 0.029 & 0.001 & -0.024 \\
\hline
\end{tabular}

Source: Community Connections and Family Wellness Study sleep data.

${ }^{+} p<.10 ;{ }^{*} p<.05 ;{ }^{* *} p<.01 ;{ }^{* * *} p<.001$

tive EDiS scores strongly predicts daily reports $(b=0.70, p<.001$; full results not shown, and coefficient is partially standardized with respect to EDiS), suggesting that despite signs of recovery, youth who report discrimination tend to on average have worse sleep. Moreover, the poor sleep factor score on the prior night does not predict daily reports of discrimination ( $b=-.08, p=.014$; results not shown), suggesting that reports of discrimination are not an outcome of poor sleep quality or poor mood $(z C E S D: b=-.13, p=.164)$.

\section{DISCUSSION}

This study examines the links between everyday discrimination, daily variations in discrimination exposure, and objective daily measures of sleep using actigraphy among a diverse sample of adolescents. It contributes to the existing literature documenting the harmful consequences of discrimination for health outcomes by demonstrating the associations between discriminatory and exclusionary experiences for objective daily measures of sleep quality in adolescence. To our knowledge, this is the first 
Table 6. Random Intercept Models, Waking, Frequency, Awake Time

\begin{tabular}{|c|c|c|c|c|c|c|}
\hline & \multicolumn{2}{|c|}{ WASO $(z)$} & \multicolumn{2}{|c|}{$\begin{array}{l}\text { Awakening } \\
\text { Frequency }(z)\end{array}$} & \multicolumn{2}{|c|}{$\begin{array}{c}\text { Average Awake } \\
\text { Time (z) }\end{array}$} \\
\hline & $\mathrm{F} 1$ & F2 & G1 & G2 & $\mathrm{H} 1$ & $\mathrm{H} 2$ \\
\hline \multicolumn{7}{|l|}{ Between youth measures } \\
\hline $\operatorname{EDiS}(z)$ & $0.218^{*}$ & & $0.217^{* *}$ & & $0.161^{*}$ & \\
\hline African American or biracial & -0.295 & -0.204 & $-0.392^{* *}$ & $-0.312^{*}$ & -0.142 & -0.073 \\
\hline Female & -0.041 & -0.024 & 0.001 & 0.028 & -0.096 & -0.091 \\
\hline Age (centered) & -0.100 & -0.358 & $-0.292^{+}$ & $-0.494^{* *}$ & 0.070 & -0.144 \\
\hline Parent married & 0.187 & 0.256 & 0.146 & 0.182 & 0.069 & 0.131 \\
\hline Number of children & 0.016 & 0.079 & 0.024 & 0.060 & 0.021 & 0.077 \\
\hline Income less than $\$ 45,000$ & -0.019 & -0.164 & -0.128 & -0.229 & 0.109 & -0.013 \\
\hline \multicolumn{7}{|c|}{ Biological between youth measures } \\
\hline $\operatorname{CRP}(z)$ & -0.009 & 0.089 & -0.008 & 0.080 & -0.014 & 0.056 \\
\hline Hba1c (z) & $0.201^{*}$ & $0.202^{*}$ & $0.364^{* * *}$ & $0.365^{* * *}$ & 0.036 & 0.038 \\
\hline $\operatorname{EBV}(z)$ & 0.052 & -0.023 & $0.162^{*}$ & 0.104 & 0.042 & -0.018 \\
\hline Waist-hip ratio $(z)$ & -0.003 & -0.090 & -0.099 & $-0.185^{*}$ & 0.064 & 0.001 \\
\hline \multicolumn{7}{|l|}{ Daily diary questions } \\
\hline Discrimination ( $t$, count) & & $-0.116^{* *}$ & & -0.026 & & -0.053 \\
\hline Discrimination $(t, a v g, z)$ & & $0.251^{* *}$ & & 0.110 & & $0.184^{*}$ \\
\hline Somatic complaints $(t, z)$ & & 0.023 & & $-0.143^{*}$ & & 0.098 \\
\hline Somatic complaints $(t, a v g, z)$ & & 0.158 & & $0.246^{*}$ & & 0.064 \\
\hline Poor SRH $(t, z)$ & & 0.045 & & 0.094 & & -0.061 \\
\hline Poor SRH $(t$, avg, $z)$ & & 0.101 & & 0.039 & & $0.164^{+}$ \\
\hline Intercept & -0.224 & 0.004 & -0.041 & 0.208 & -0.329 & -0.200 \\
\hline \multicolumn{7}{|l|}{ Variance components } \\
\hline Between subject $(I n)$ & $-1.011^{* * *}$ & $-1.106^{* * *}$ & $-1.498^{* * *}$ & $-1.460^{* * *}$ & $-1.452^{* * *}$ & $-1.742^{* * *}$ \\
\hline Residual (In) & $-0.082^{*}$ & $-0.097^{* *}$ & $-0.104^{* *}$ & $-0.113^{* *}$ & -0.050 & -0.057 \\
\hline AR1 (rho) & $0.127^{*}$ & $0.096^{+}$ & $0.129^{*}$ & $0.120^{*}$ & $0.210^{* * *}$ & $0.199 * * *$ \\
\hline
\end{tabular}

Source: Community Connections and Family Wellness Study sleep data.

${ }^{+} p<.10 ;{ }^{*} p<.05 ;{ }^{* *} p<.01 ;{ }^{* *} p<.001$

study to concurrently measure both retrospective reports of Everyday Discrimination (EDiS) and daily diary reports of discrimination with concurrent objective sleep measures.

The findings support our first hypothesis that average sleep would be linked to discrimination. In fact, average discrimination, operationalized using the retrospective EDiS scale was associated with poorer sleep outcomes across all but two included measures. In general, youth who report more discrimination had shorter sleep duration and poorer sleep quality. Specifically, on indicators of sleep duration, youth who reported discrimination took longer to fall asleep (latency), had less efficient sleep, and spent more time in bed but less time asleep. In terms of sleep quality, youth who reported discrimination had more awakenings after sleep onset, longer duration awake during a sleep disruption, moved more while asleep and had more fragmented sleep. This study falls in line with research using gold standard laboratory techniques finding evidence among adults that discrimination exposure is linked to less time in restorative slow wave sleep (stage 4) (Thomas et al. 2006).

Hypothesis 2 posited that day-to-day variation in perceived discrimination would be adversely associated with sleep variability around the person-average. Thus hypothesis 2 is a 
Table 7. Random Intercept Models, Movement, Fragmentation Index, Sleep Fragmentation Index

\begin{tabular}{|c|c|c|c|c|c|c|}
\hline & \multicolumn{2}{|c|}{$\begin{array}{l}\text { Movement } \\
\text { Index (z) }\end{array}$} & \multicolumn{2}{|c|}{$\begin{array}{l}\text { Fragmentation } \\
\text { Index }(z)\end{array}$} & \multicolumn{2}{|c|}{$\begin{array}{l}\text { Sleep Fragmentation } \\
\text { Index }(z)\end{array}$} \\
\hline & $\mid 1$ & 12 & J1 & $\mathrm{J} 2$ & K1 & $\mathrm{K} 2$ \\
\hline \multicolumn{7}{|l|}{ Between youth measures } \\
\hline EDiS $(z)$ & $0.283^{* *}$ & & 0.110 & & $0.239 * *$ & \\
\hline African American or biracial & -0.208 & -0.092 & 0.140 & 0.192 & -0.046 & 0.054 \\
\hline Female & 0.021 & 0.077 & -0.035 & -0.051 & -0.009 & 0.015 \\
\hline Age (centered) & -0.227 & $-0.402^{+}$ & 0.105 & -0.141 & -0.098 & $-0.350^{+}$ \\
\hline Parent married & 0.201 & $0.300^{+}$ & 0.113 & 0.157 & 0.183 & $0.268^{+}$ \\
\hline Number of children & 0.033 & $0.123^{*}$ & -0.005 & 0.034 & 0.017 & 0.095 \\
\hline Income less than $\$ 45,000$ & -0.086 & $-0.308^{+}$ & -0.010 & -0.083 & -0.048 & -0.226 \\
\hline \multicolumn{7}{|l|}{$\begin{array}{l}\text { Biological between youth } \\
\text { measures }\end{array}$} \\
\hline $\operatorname{CRP}(z)$ & -0.015 & $0.182^{+}$ & -0.019 & -0.006 & -0.018 & 0.108 \\
\hline Hba1c $(z)$ & $0.171^{+}$ & $0.155^{+}$ & $0.153^{*}$ & $0.164^{* *}$ & $0.196^{*}$ & $0.192^{\star *}$ \\
\hline $\mathrm{EBV}(z)$ & 0.013 & -0.106 & 0.023 & -0.009 & 0.033 & -0.060 \\
\hline Waist-hip ratio $(z)$ & -0.006 & -0.095 & 0.038 & -0.020 & 0.014 & -0.075 \\
\hline \multicolumn{7}{|l|}{ Daily diary questions } \\
\hline Discrimination ( $t$, count) & & $-0.119^{* *}$ & & $-0.108^{*}$ & & $-0.134^{* *}$ \\
\hline Discrimination ( $t$, avg, $z$ ) & & $0.362^{* * *}$ & & $0.160^{*}$ & & $0.315^{* * *}$ \\
\hline Somatic complaints $(t, z)$ & & $0.179 * *$ & & 0.016 & & $0.120^{+}$ \\
\hline Somatic complaints ( $(t, a v g, z)$ & & 0.072 & & 0.102 & & 0.101 \\
\hline Poor SRH $(t, z)$ & & 0.043 & & -0.090 & & -0.021 \\
\hline Poor SRH $(t$, avg, $z)$ & & 0.027 & & $0.216^{*}$ & & 0.141 \\
\hline Intercept & -0.299 & -0.116 & -0.325 & -0.156 & -0.369 & -0.156 \\
\hline \multicolumn{7}{|l|}{ Variance components } \\
\hline Between subject $(I n)$ & $-0.943^{* * *}$ & $-1.078^{* * *}$ & $-1.349 * * *$ & $-1.613^{* * *}$ & $-1.050 * * *$ & $-1.233^{* * *}$ \\
\hline Residual (In) & $-0.109^{* *}$ & $-0.132^{* * *}$ & $-0.074^{*}$ & $-0.081^{*}$ & $-0.093^{* *}$ & $-0.111^{* *}$ \\
\hline AR1 (rho) & $0.107^{+}$ & 0.068 & 0.078 & $0.093^{+}$ & $0.121^{*}$ & $0.094^{+}$ \\
\hline
\end{tabular}

Source: Community Connections and Family Wellness Study data.

${ }^{+} p<.10 ;{ }^{*} p<.05 ;{ }^{* *} p<.01 ;{ }^{* * *} p<.001$

within-person hypothesis, suggesting discrimination as a potential source of individual variability in sleep quality. This hypothesis was consistently contradicted by our results, which suggest that contemporaneous exposure is linked to improved sleep efficiency, longer total sleep time, less time awake after sleep onset, and decreased movement and sleep fragmentation. Given that youth more likely to report discrimination having happened over the course of the day are generally more likely to report accumulated everyday discrimination, these results suggest a partial recovery in sleep quality following the negative experience. It is important, however, that despite daily indications of improved sleep on the day of the event, the average sleep duration and quality remain lower in youth who report discriminatory events. In general, around three discriminatory experiences in one day would be required to make up for the average decrease in sleep quality over days across those sleep features given the effect sizes estimated.

In her study measuring discrimination exposure and minority youth psychological wellbeing, Yip posits that for minority youth who experience discrimination, sleep may in fact be a health coping mechanism that lessens the 
deleterious impact of discrimination in the short term (2014). Her study finds that youth who experience discrimination and have better daily sleep quality experience higher selfesteem and lower depressive symptoms. It does not, however, contemporaneously measure both daily sleep and discrimination exposure contemporaneously, pointing to the need for more research with larger and more diverse samples using designs similar to those in this study.

An important unmeasured component in this study that may shed light on our surprising results and merits examination is the role of active coping style in the face of social stressors. Sleep is an essential component for healthy adolescent development, yet variations in how coping styles impact sleep or how sleep can be used as a coping tool have yet to be systematically examined. Escape to sleep describes how individuals who have disengaged coping styles may use sleep to regulate exposure to adverse stressful emotions or social conditions. Conversely, individuals who engage in more emotionally focused coping may interpret sleep as a loss of mastery and thus are more prone to heightened arousal and sleep disruption (Sadeh, Keinan, and Daon 2004). Although this study does not include specific measures of coping styles, integrating behavioral and emotional coping among diverse populations is an important direction to take future research in this area.

Despite the novelty of these findings, this study is limited in several important ways. First, although actigraphy provides validated objective measures of sleep quality and duration, validation studies indicate that actigraphs can suffer from low specificity or accuracy when detecting wakefulness, which may affect a number of sleep indices (Sadeh 2011). However, it has been suggested that aggregate data over at least four to five nights can compensate for this issue. This study includes fourteen days of data. Second, the sample size is both small and is based on convenience sample in a single community. Obviously, more powerful samples, and samples constructed using state-ofthe-art sampling methodologies are important for better characterizing sleep variability and enhancing generalizability to broader popula- tions. Finally, though racial and ethnic heterogeneity was also low, the racial diversity in this sample is mostly biracial youth with an African American parent, which is novel. More diversity, however, is needed for understanding how the experience of discrimination shapes sleep and health over the early life course.

Overall, discrimination is consistently related to poorer sleep and poor sleep appears to be related to an important long-term health marker already by adolescence. Moreover, supplementary analyses indicated that sleep did not predict discrimination reports the following day, and measures of depressive symptoms did not predict sleep or mediate the discrimination parameters. Taken together, these results support the small but growing literature demonstrating the harmful consequences of discrimination for sleep health and the extensive literature demonstrating the association between discrimination and health risk (Slopen, Lewis, and Williams 2016; Williams 2012).

\section{REFERENCES}

ActiGraph. 2012. "ActiLife 6 User's Manual." ActiGraph SFT12DOC13(A).

Åkerstedt, Torbjörn. 2006. “Psychosocial Stress and Impaired Sleep." Scandinavian Journal of Work, Environment \& Health 32(6): 493-501.

Åkerstedt, Torbjörn, Göran Kecklund, and John Axelsson. 2007. "Impaired Sleep After Bedtime Stress and Worries." Biological Psychology 76(3): 170-73. DOI: 10.1016/j.biopsycho.2007.07.010.

Allison, Paul D. 2005. Fixed Effects Regression Methods for Longitudinal Data Using SAS. Cary, N.C.: SAS Institute, Inc.

Ancoli-Israel, S., Roger Cole, Cathy Alessi, Mark Chambers, William Moorcroft, and Charles P. Pollak. 2003. "The Role of Actigraphy in the Study of Sleep and Circadian Rhythms." Sleep 26(3): 342-92.

Balbo, Marcella, Rachel Leproult, and Eve Van Cauter. 2010. "Impact of Sleep and Its Disturbances on Hypothalamo-Pituitary-Adrenal Axis Activity." International Journal of Endocrinology 2010. DOI: 10.1155/2010/759234.

Baumeister, Roy F., and Mark R. Leary. 1995. “The Need to Belong: Desire for Interpersonal Attachments as a Fundamental Human Motivation." Psychological Bulletin 117(3): 497-529.

Becker, Stephen P., Joshua M. Langberg, and Kelly C. 
Byars. 2015. "Advancing a Biopsychosocial and Contextual Model of Sleep in Adolescence: A Review and Introduction to the Special Issue." Journal of Youth and Adolescence 44(2): 239-70. DOI: 10.1007/s10964-014-0248-y.

Benjamins, M. R. 2012. “Race/Ethnic Discrimination and Preventive Service Utilization in a Sample of Whites, Blacks, Mexicans, and Puerto Ricans." Med Care 50(10): 870-76. DOI: 10.1097/MLR .0b013e31825a8c63.

Brody, Gene H., Man-Kit Lei, David H. Chae, Tianyi Yu, Steven M. Kogan, and Steven R. H. Beach. 2014. "Perceived Discrimination Among African American Adolescents and Allostatic Load: A Longitudinal Analysis with Buffering Effects." Child Development 85(3): 989-1002. DOI: 10.1111 /cdev.12213.

Burbidge, John B., Lonnie Magee, and A. Leslie Robb. 1988. "Alternative Transformations to Handle Extreme Values of the Dependent Variable." Journal of the American Statistical Association 83(401): 123-27. DOI: 10.2307/2288929.

Cacioppo, John T., and William Patrick. 2009. Loneliness: Human Nature and the Need for Social Connection. New York: W. W. Norton.

Carskadon, Mary A. 1990. "Patterns of Sleep and Sleepiness in Adolescents." Journal of Adolescent Health 17(1): 5-12.

CFIN. 2012. The Face of Poverty Today in Lincoln, NE. Lincoln, Neb.: Center for People in Need.

Chi, Eric M., and Gregory C. Reinsel. 1989. “Models for Longitudinal Data with Random Effects and AR(1) Errors." Journal of the American Statistical Association 84(406): 452-59. DOI: 10.1080 /01621459.1989.10478790.

Dahl, Ronald E. 1999. “The Consequences of Insufficient Sleep for Adolescents." Phi Delta Kappan 80(5): 354-59.

Dalton, M., A. J. Cameron, P. Z. Zimmet, J. E. Shaw, D. Jolley, D. W. Dunstan, T. A. Welborn, and Committee on Behalf of the AusDiab Steering. 2003. “Waist Circumference, Waist-Hip Ratio and Body Mass Index and Their Correlation with Cardiovascular Disease Risk Factors in Australian Adults." Journal of Internal Medicine 254(6): 55563. DOI: 10.1111/j.1365-2796.2003.01229.x.

Duclos, Rod, Echo Wen Wan, and Yuwei Jiang. 2014. "Show Me the Money! Effects of Social Exclusion on Financial Risk-Taking." Journal of Consumer Research 40(1): 122-35.

El-Sheikh, Mona, Ryan J. Kelly, Joseph A. Buckhalt, and J. Benjamin Hinnant. 2010. “Children's Sleep and Adjustment over Time: The Role of Socioeconomic Context." Child Development 81(3): 870-83. DOI: 10.1111/j.1467-8624.2010.01439.x.

Eufemia, Jacob, Jennifer Stinson, Joana Duran, Ankur Gupta, Mario Gerla, Mary Ann Lewis, and Lonnie Zeltzer. 2012. “Usability Testing of a Smartphone for Accessing a Web-Based E-Diary for Self-Monitoring of Pain and Symptoms in Sickle Cell Disease." Journal of Pediatric Hematology and Oncology 34(5): 326-35. DOI: 10.1097 /MPH.0b013e318257a13c.

Falk, Emily B., Luke W. Hyde, Colter Mitchell, Jessica Faul, et al. 2013. “What Is a Representative Brain? Neuroscience Meets Population Science." Proceedings of the National Academy of Sciences 110(44): 17615-22.

Goosby, Bridget J., Sarah Malone, Elizabeth A. Richardson, Jacob E. Cheadle, and Deadric T. Williams. 2015. “Perceived Discrimination and Markers of Cardiovascular Risk Among Low-Income African American Youth." American Journal of Human Biology 27(4): 546-52. DOI: 10.1002/ ajhb.22683.

Gregory, Alice M., and Avi Sadeh. 2012. “Sleep, Emotional and Behavioral Difficulties in Children and Adolescents." Sleep Medicine Reviews 16(2): 12936. DOI: 10.1016/j.smrv.2011.03.007.

Guyll, Max, Karen A. Matthews, and Joyce T. Bromberger. 2001. “Discrimination and Unfair Treatment: Relationship to Cardiovascular Reactivity Among African American and European American Women." Health Psychology 20(5): 315-25. DOI: 10.1037/0278-6133.20.5.315.

Hale, Lauren, and D. Phuong Do. 2007. “Racial Differences in Self-Reports of Sleep Duration in a Population-Based Study." Sleep 30(9): 1096-103.

Hale, Lauren, Erin Emanuele, and Sarah James. 2015. "Recent Updates in the Social and Environmental Determinants of Sleep Health." Current Sleep Medicine Reports 1(4): 212-17. DOI: 10.1007 /s40675-015-0023-y.

Hawkley, Louise C., Mary H. Burleson, Gary G. Berntson, and John T. Cacioppo. 2003. "Loneliness in Everyday Life: Cardiovascular Activity, Psychosocial Context, and Health Behaviors." Journal of Personality Social Psychology 85(1): 105-20.

Hicken, Margaret T., Hedwig Lee, Jennifer Ailshire, Sarah A. Burgard, and Deadric R. Williams. 2013. “'Every Shut Eye, Ain't Sleep': The Role of Racism-Related Vigilance in Racial/Ethnic Dis- 
parities in Sleep Difficulty." Race and Social Problems 5(2): 100-12. DOI: 10.1007/s12552-013 -9095-9.

Hope, Elan C., Lori S. Hoggard, and Alvin Thomas. 2015. “Emerging into Adulthood in the Face of Racial Discrimination: Physiological, Psychological, and Sociopolitical Consequences for African American Youth." Translational Issues in Psychological Science 1(4): 342-51. DOI: 10.1037/tps 0000041.

Irwin, Michael R. 2015. "Why Sleep Is Important for Health: A Psychoneuroimmunology Perspective." Annual Review of Psychology 66(1): 143-72. DOI: 10.1146/annurev-psych-010213-115205.

Kim, Giyeon, Martin Sellbom, and Katy-Lauren Ford. 2014. "Race/Ethnicity and Measurement Equivalence of the Everyday Discrimination Scale." Psychological Assessment 26(3): 892-900. DOI: 10 .1037/a0036431.

Kingsbury, John H., Orfeu M. Buxton, and Karen M. Emmons. 2013. “Sleep and Its Relationship to Racial and Ethnic Disparities in Cardiovascular Disease." Current Cardiovascular Risk Reports 7(5): 387-94. DOI: 10.1007/s12170-013-0330-0.

Kliewer, Wendy, and Stephen J. Lepore. 2014. “Exposure to Violence, Social Cognitive Processing, and Sleep Problems in Urban Adolescents." Journal of Youth and Adolescence 44(2): 507-17. DOI: 10.1007/s10964-014-0184-x.

Krieger, Nancy, Anna Kosheleva, Pamela D. Waterman, Jarvis T. Chen, and Karestan Koenen. 2011. “Racial Discrimination, Psychological Distress, and Self-Rated Health Among US-Born and Foreign-Born Black Americans." American Journal of Public Health 101(9): 1704-13. DOI: 10.2105 /AJPH.2011.300168.

Krieger, Nancy, Kevin Smith, Deepa Naishadham, Cathy Hartman, and Elizabeth M. Barbeau. 2005. "Experiences of Discrimination: Validity and Reliability of a Self-Report Measure for Population Health Research on Racism and Health." Social Science \& Medicine 61(7): 1576-96. DOI: 10.1016 /j.socscimed.2005.03.006.

Krueger, Patrick M., and Elliot M. Friedman. 2009. "Sleep Duration in the United States: A CrossSectional Population-Based Study." American Journal of Epidemiology 169(9): 1052-63. DOI: 10.1093/aje/kwp023.

Lewis, Tené T., Allison E. Aiello, Sue Leurgans, Jeremiah Kelly, and Lisa L. Barnes. 2010. “SelfReported Experiences of Everyday Discrimination
Are Associated with Elevated C-Reactive Protein Levels in Older African-American Adults." Brain, Behavior, and Immunity 24(3): 438-43. DOI:10 .1016/j.bbi.2009.11.011.

Lewis, Tené T., Lisa L. Barnes, Julia L. Bienias, Daniel T. Lackland, Denis A. Evans, and Carlos F. Mendes de Leon. 2009. "Perceived Discrimination and Blood Pressure in Older African American and White Adults." Journals of Gerontology Series A: Biological Sciences and Medical Sciences 64A(9): 1002-08.

Lewis, Tené T., Howard M. Kravitz, Imke Janssen, and Lynda H. Powell. 2011. "Self-Reported Experiences of Discrimination and Visceral Fat in Middle-Aged African-American and Caucasian Women." American Journal of Epidemiology 173(11): 1223-31. DOI: 10.1093/aje/kwq466.

Lewis, Tené T., Wendy M. Troxel, Howard M. Kravitz, Joyce T. Bromberger, Karen A. Matthews, and Martica Hall. 2013. “Chronic Exposure to Everyday Discrimination and Sleep in a Multi-Ethnic Sample of Middle-Aged Women." Health Psychology 32(7): 810-19. DOI: 10.1037 /a0029938.

Marino, Miguel, Yi Li, Michael N. Rueschman, John W. Winkelman, J. M. Ellenbogen, Jo M. Solet, Hilary Dulin, Lisa F. Berkman, and Orfeu M. Buxton. 2013. “Measuring Sleep: Accuracy, Sensitivity, and Specificity of Wrist Actigraphy Compared to Polysomnography." Sleep 36(11): 1747-55. DOI: 10 $.5665 /$ sleep.3142.

Massey, Douglas S. 2004. "Segregation and Stratification: A Biosocial Perspective." Du Bois Review: Social Science Research on Race 1(1): 7-25.

McClure, Heather H., Charles R. Martinez, Jr., J. Josh Snodgrass, J. Mark Eddy, Roberto A. Jiménez, Laura E. Isiordia, and Thomas W. McDade. 2010. “Discrimination-Related Stress, Blood Pressure and Epstein-Barr Virus Antibodies Among Latin American Immigrants in Oregon, US." Journal of Biosocial Science 42(4): 433-61. DOI: 10.1017 /S0021932010000039.

Mezick, Elizabeth J., Karen A. Matthews, Martica Hall, Patrick J. Strollo Jr., Daniel J. Buysse, Thomas W. Kamarck, Jane F. Owens, and Steven E. Reis. 2008. "Influence of Race and Socioeconomic Status on Sleep: Pittsburgh SleepSCORE Project." Psychosomatic Medicine 70(4): 410-16. DOI: 10.1097/PSY.0b013e31816fdf21.

Paradies, Yin. 2006. "A Systematic Review of Empirical Research on Self-Reported Racism and 
Health." International Journal of Epidemiology 35(4): 888-901. DOI: 10.1093/ije/dyl056.

Park, Heejung, Kim M. Tsai, Ronald E. Dahl, Michael R. Irwin, Heather McCreath, Teresa Seeman, and Andrew J. Fuligni. 2016. "Sleep and Inflammation During Adolescence." Psychosomatic Medicine 78(6): 677-85.

Pearson, Thomas A., George A. Mensah, R. Wayne Alexander, Jeffrey L. Anderson, et al. 2003. “Markers of Inflammation and Cardiovascular Disease: Application to Clinical and Public Health Practice: A Statement for Healthcare Professionals from the Centers for Disease Control and Prevention and the American Heart Association." Circulation 107(3): 499-511.

Pereira, Diana, Lawrence L. Meier, and Achim Elfering. 2013. "Short-Term Effects of Social Exclusion at Work and Worries on Sleep." Stress and Health: Journal of the International Society for the Investigation of Stress 29(3): 240-52.

Priest, Naomi, Yin Paradies, Brigid Trenerry, Mandy Truong, Saffron Karlsen, and Yvonne Kelly. 2013. "A Systematic Review of Studies Examining the Relationship Between Reported Racism and Health and Wellbeing for Children and Young People." Social Sciences Medicine 95 (October): 115-27. DOI: 10.1016/j.socscimed.2012.11.031.

Profant, Judi, Sonia Ancoli-Israel, and Joel E. Dimsdale. 2002. "Are There Ethnic Differences in Sleep Architecture?" American Journal of Human Biology 14(3): 321-26. DOI: 10.1002/ajhb.10032.

Raudenbush, Stephen W., and Anthony S. Bryk. 2002. Hierarchical Linear Models: Applications and Data Analysis Methods, 2nd ed. Thousand Oaks, Calif.: Sage Publications.

Sadeh, Avi. 2011. "The Role and Validity of Actigraphy in Sleep Medicine: An Update." Sleep Medicine Reviews 15(4): 259-67. DOI: 10.1016/j.smrv .2010.10.001.

Sadeh, Avi, Giora Keinan, and Keren Daon. 2004. “Effects of Stress on Sleep: The Moderating Role of Coping Style." Health Psychology 23(5): 542-45. DOI: 10.1037/0278-6133.23.5.542.

Sadeh, Avi, Katherine M. Sharkey, and Mary A. Carskadon. 1994. "Activity-Based Sleep-Wake Identification: An Empirical Test of Methodological Issues." Sleep 17(3): 201-07.

Schmitt, Michael T., Nyla R. Branscombe, Tom Postmes, and Amber Garcia. 2014. “The Consequences of Perceived Discrimination for Psycho- logical Well-Being: A Meta-Analytic Review." Psychological Bulletin 140(4): 1-28.

Shariff-Marco, Salma, Nancy Breen, Hope Landrine, Bryce B. Reeve, Nancy Krieger, Gilbert C. Gee, David R. Williams, Vickie M. Mays, Ninez A. Ponce, and Margarita Alegria. 2011. “Measuring Everyday Racial/Ethnic Discrimination in Health Surveys." Du Bois Review 8(1): 159-77.

Short, Michelle A., Michael Gradisar, Leon C. Lack, Helen R. Wright, and Mary A. Carskadon. 2012. “The Discrepancy Between Actigraphic and Sleep Diary Measures of Sleep in Adolescents." Sleep Medicine 13(4): 378-84. DOI: 10.1016/j sleep.2011.11.005.

Short, Michelle A., Michael Gradisar, Leon C. Lack, Helen R. Wright, and Alex Chatburn. 2013. “Estimating Adolescent Sleep Patterns: Parent Reports Versus Adolescent Self-Report Surveys, Sleep Diaries, and Actigraphy." Nature and Science of Sleep 5(1): 23-26.

Sladek, Michael R., and Leah D. Doane. 2014. “Daily Diary Reports of Social Connection, Objective Sleep, and the Cortisol Awakening Response During Adolescents' First Year of College." Journal of Youth and Adolescence 44(2): 298-316. DOI: 10.1007/s10964-014-0244-2.

Slopen, Natalie, Tené T. Lewis, and David R. Williams. 2016. “Discrimination and Sleep: A Systematic Review." Sleep Medicine 18 (February): 88-95. DOI: 10.1016/j.sleep.2015.01.012.

Thomas, Kamala S., Wayne A. Bardwell, Sonia Ancoli-Israel, and Joel E. Dimsdale. 2006. “The Toll of Ethnic Discrimination on Sleep Architecture and Fatigue." Health Psychology 25(5): 635-42.

Torres, Lucas, and Anthon D. Ong. 2010. “A Daily Diary Investigation of Latino Ethnic Identity, Discrimination, and Depression." Cultural Diversity and Ethnic Minority Psychology 16(4): 561-68.

Troiano, Richard P., David Berrigan, Kevin W. Dodd, Louise C. Masse, Timothy Tilert, and Margaret McDowell. 2008. "Physical Activity in the United States Measured by Accelerometer." Medicine \& Science in Sports \& Exercise 40(1): 181-88. DOI: 10.1249/mss.0b013e31815a51b3.

Williams, David R. 2012. "Miles to Go Before We Sleep: Racial Inequities in Health." Journal of Health and Social Behavior 53(3): 279-95. DOI: $10.1177 / 0022146512455804$.

Williams, David R., Yu Yan, James S. Jackson, and Norman B. Anderson. 1997. “Racial Differences in 
Physical and Mental Health: Socio-Economic Status, Stress and Discrimination." Journal of Health Psychology 2(3): 335-51.

Wolfson, Amy R., Mary A. Carskadon, Christine Acebo, Ronald Seifter, Gahan Fallone, Susan E. Layak, and Jennifer Martin. 2003. “Evidence for the Validity of a Sleep Habits Survey for Adolescents." Sleep 26(3): 213-16.

Wong, Carol A., Jacquelynne S. Eccles, and Arnold Sameroff. 2003. "The Influence of Ethnic Dis- crimination and Ethnic Identification on African American Adolescents' School and Socioemotional Adjustment." Journal of Personality 71(6): 1197-232. DOI: 10.1111/1467-6494.7106012.

Yip, Tiffany. 2014. “The Effects of Ethnic/Racial Discrimination and Sleep Quality on Depressive Symptoms and Self-Esteem Trajectories Among Diverse Adolescents." Journal of Youth and Adolescence 44(2): 419-30. DOI: 10.1007/s10964 -014-0123-x. 